\title{
The Development of Sulfate Scale Inhibitor for RO System
}

\author{
Kecheng Liu ${ }^{1, a}$, Xiao Long ${ }^{1, b}$, Mengsha $\mathrm{Hu}^{2, \mathrm{c}}$ and Baiqing Zhou ${ }^{2, \mathrm{~d}}$ \\ ${ }^{1}$ Hebei Electric Power Commissioning Institute, Shijiazhuang 050021, China;
}

${ }^{2}$ School of Power and Mechanical Engineering, Wuhan University, Wuhan 430072, China.

aliukc2015@126.com, b13832168901@126.com, chms09141619@163.com, dbqzhou@whu.edu.cn

Keywords: RO, sulfate, scale inhibitor

Abstract. This paper develops the sulfate scale inhibitor WUR-201 for RO using uniform design method, and the results show that the scale inhibition performance of WUR-201 can reach or even exceed that of scale inhibitor Foreign 1\#; the scale inhibition ability increases with $\mathrm{pH}$ increasing but decreases with temperature increasing; $\mathrm{Fe}^{3+}$ and $\mathrm{Al}^{3+}$ can lead to WUR-201 poisoning; WUR-201 has also good scale inhibition for $\mathrm{CaCO}_{3}$.

\section{Introduction}

According to the investigation, $85 \%$ of the operational failure of reverse osmosis (RO) system in China is caused by the pretreatment. And the main form of the operational failure is the membrane parts pollution and plugging, and the property includes biological slime and scaling substance. The primary preventive measure of biological slime is sterilization management. Different kinds of scaling substance need different preventive measures, for example, measures such as the acid addition, scale inhibitors addition and water softening can be taken for carbonate scale.

In China the primary scaling substance threatening the operation of $\mathrm{RO}$ system are $\mathrm{CaCO}_{3}$ and sulfate (including $\mathrm{BaSO}_{4}, \mathrm{SrSO}_{4}$ and $\mathrm{CaSO}_{4}$ ). To prevent the scaling of $\mathrm{RO}$ system, some foreign special scale inhibitors for RO have been developed, such as PTP-2000, PTP-0100, Flocon 260, SJ-881, TPT-0510, LA302, TianASD 200/SC and so on, which have been used in China. However, these inhibitors are expensive, and scale inhibitors for sulfate are few. Thus, the sulfate scale inhibitor WUR-201 is developed in this paper compared with the control, that is the foreign inhibitor.

\section{Materials and Methods}

Table 1 gives the preparation of the experimental water. After the scale inhibitors are mixed with a certain volume of experimental water, keep the water at the constant temperature for a certain time, and then determine the scale inhibition rate $(\eta)$.

Table 1 Test Conditions

\begin{tabular}{ccc}
\hline & $\begin{array}{c}\text { Experimental Water } \\
\text { Scaling Substance } \\
\mathrm{BaSO}_{4}\end{array}$ & Water Temperature/ \\
$\mathrm{SrSO}_{4}$ & $\rho\left(\mathrm{Ba}^{2+}\right)=400, \rho\left(\mathrm{SO}_{4}{ }^{2-}\right)=1200$ & $60 \pm 1$ \\
$\mathrm{CaSO}_{4}$ & $\rho\left(\mathrm{Sr}^{2+}\right)=438, \rho\left(\mathrm{SO}_{4}{ }^{2-}\right)=480$ & $60 \pm 1$ \\
$\mathrm{CaCO}_{3}$ & $\rho\left(\mathrm{Ca}^{2+}\right)=2000, \rho\left(\mathrm{SO}_{4}{ }^{2-}\right)=4800$ & $80 \pm 1$ \\
& $\rho\left(\mathrm{Ca}^{2+}\right)=400, \rho\left(\mathrm{HCO}_{3}{ }^{-}\right)=1200$ & $80 \pm 1$ \\
\hline
\end{tabular}

\section{Experimental Results}

In this paper the scale inhibition rates for $\mathrm{BaSO}_{4}, \mathrm{SrSO}_{4}$ and $\mathrm{CaSO}_{4}$ are respectively denoted by $\eta \mathrm{Ba}, \quad \eta \mathrm{Sr}$ and $\eta \mathrm{Ca}$. 


\section{Scale Inhibition Performance of Monomer}

In order to compound the inhibitor, the sulfate scale inhibition performance of four kinds of monomers (respectively numbered A, B, C and D) are determined. These monomers include ATMP, EDTMP, HEDP, DETPMP, PBTCA and HPMA. And two kinds of RO running conditions have been taken into account, that is acidification operation ( $\mathrm{pH}$ of concentrate is about 6.5) and operation without acid ( $\mathrm{pH}$ of concentrate is about 8.5 ).

Table 2 gives the results and the usage amount of the inhibitors (Dn) is $9 \mathrm{mg} / \mathrm{L}$. The order of the inhibition difficulty of three kinds of sulfate is as follows: $\mathrm{BaSO}_{4}>\mathrm{SrSO}_{4}>\mathrm{CaSO}_{4}$. And for $\mathrm{BaSO}_{4}$, the scaling substance most difficult to control, the order of the scale inhibition performance is $\mathrm{D}>\mathrm{C}>\mathrm{A}>\mathrm{B}$, which should be payed attention to when selecting inhibitors.

Table 2 Scale Inhibition Rates of Monomer (\%)

\begin{tabular}{ccccccc}
\hline $\begin{array}{c}\text { Scaling Substance } \\
\text { pH }\end{array}$ & \multicolumn{2}{c}{$\mathrm{BaSO}_{4}$} & \multicolumn{2}{c}{$\mathrm{SrSO}_{4}$} & \multicolumn{2}{c}{$\mathrm{CaSO}_{4}$} \\
A & 2.5 & 8.5 & 6.5 & 8.5 & 6.5 & 8.5 \\
B & 1.03 & 17.82 & 22.33 & 56.33 & 68.23 & 66.9 \\
C & 5.94 & 43.67 & 56.12 & 49.02 & 50.78 \\
D & 20.11 & 36.28 & 52.09 & 70.58 & 74.66 & 75.23 \\
\hline
\end{tabular}

Scale Inhibition Performance of Compound Medicine

In order to make the most of synergistic effect of the inhibitors, taking the dispersing ability and inhibiting ability of biological sludge into account, three series (respectively numbered X, Y and Z), that is eighteen kinds of complex formulations of those monomers are made, and the initial tests show that the $\mathrm{X}$ series has good scale inhibition performance.

To improve the inhibition performance further, the $\mathrm{X}$ series is optimized. The technical route is as follows: (1) Determine the formulation composition according to the uniform design table. (2) Measure the scale inhibition rates of these formulations. (3) Use the resulting data to build a mathematical model of the relationship between scale inhibition rates and the complex formulations, then utilize the regression analysis to determine the coefficients in above model. (4) Utilize the F-Test to select the most important factors and remove the secondary factors, getting the experiential formula. (5) Solve the conditional maximum value of the experiential formula (multivariate function) and get the best formulation, which is called WUR-201. (6) Measure the scale inhibition rate of WUR-201.

Table 3 gives the computational and verified values, and the test results are in concordance with the results of calculation.

Table 3 The Computational and Verified Scale Inhibition Rates of WUR-201 (\%)

\begin{tabular}{ccccccc}
\hline Scaling Substance & \multicolumn{2}{c}{$\mathrm{BaSO}_{4}$} & \multicolumn{2}{c}{$\mathrm{SrSO}_{4}$} & \multicolumn{2}{c}{$\mathrm{CaSO}_{4}$} \\
\hline $\mathrm{pH}$ & 6.5 & 8.5 & 6.5 & 8.5 & 6.5 & 8.5 \\
Computational Value & 64.20 & 77.63 & 100.00 & 100.00 & 98.45 & 99.14 \\
Verified Value & 67.16 & 80.78 & 100.00 & 100.00 & 95.55 & 96.98 \\
\hline
\end{tabular}

The Comparison Between WUR-201 and The Foreign Inhibitor

The contrast test is conducted for WUR-201 and a foreign sulfate scale inhibitor (called Foreign $1 \#)$. The results are as follows:

(1) Scale Inhibition Performance

Fig. 1 shows the changing curves of scale inhibition rates of WUR-201 and Foreign $1 \#$ for $\mathrm{BaSO}_{4}, \mathrm{SrSO}_{4}$ and $\mathrm{CaSO}_{4}$ at different dosages and $\mathrm{pH}$ of 8.5.

According to Fig. 1, the scale inhibition rates of WUR-201 for $\mathrm{BaSO}_{4}, \mathrm{SrSO}_{4}$ and $\mathrm{CaSO}_{4}$ exceed Foreign 1\#. For example, at the dosage of 12mg/L, $\eta \mathrm{Ba}, \eta \mathrm{Sr}$ and $\eta \mathrm{Ca}$ of WUR-201 are respectively $15.8 \%, 29.7 \%$ and $8 \%$ higher than Foreign $1 \#$.

(2) The Influence of $\mathrm{pH}$

Fig. 2 shows the influence of $\mathrm{pH}$ on WUR-201 and Foreign 1\# at the dosage of 9mg/L. Overall 
their inhibition ability increases as $\mathrm{pH}$ increases, and one possible reason is that under the condition of higher $\mathrm{pH}$ the ionization of the inhibitors increases, so the molecule can be more free, its adsorption capacity becomes more significant and it will have more efficiency.

What's more, Fig. 2 remains us to raise the dosage appropriately when the RO system is under the acidification operation. And we can estimate the dosage of WUR-201 or Foreign 1\# should be raised about 60\% under the acidification operation according to Fig. 1 and Fig. 2.

(3) The Influence of $\mathrm{Fe}^{3+}$

$\mathrm{Fe}^{3+}$ is the common ion in natural water and ferric salt is also the common flocculant. Although $\rho\left(\mathrm{Fe}^{3+}\right)$ can be reduced to less than $0.1 \mathrm{mg} / \mathrm{L}$ after the RO pretreatment unit, the concentration of $\mathrm{Fe}^{3+}$ will possibly increase when the coagulation facility or the groundwater aeration device isn't operating properly. Therefore it is necessary to examine inhibitor's resistance to $\mathrm{Fe}^{3+}$.

Fig. 3 gives the influence of $\mathrm{Fe}^{3+}$ on WUR-201 and Foreign $1 \#$ at the dosage of $9 \mathrm{mg} / \mathrm{L}$ and $\mathrm{pH}$ of 8.5. The results are as follows: (1) For $\mathrm{BaSO}_{4}$ scale, the resistance to $\mathrm{Fe}^{3+}$ of WUR-201 is much better than Foreign 1\#. (2) For $\mathrm{SrSO}_{4}$ sale, the influence of $\mathrm{Fe}^{3+}$ on WUR-201 is also smaller than Foreign 1\#. (3) For $\mathrm{CaSO}_{4}$ scale, Foreign $1 \#$ is more likely to be influenced by $\mathrm{Fe}^{3+}$. When increasing $\rho\left(\mathrm{Fe}^{3+}\right)$ from $0.2 \mathrm{mg} / \mathrm{L}$ to $0.5 \mathrm{mg} / \mathrm{L}$, $\eta$ Ca of Foreign 1 \# decreases $26.9 \%$ while $\eta$ Ca of WUR-201 decreases only 2.8\%. In a word, the resistance to $\mathrm{Fe}^{3+}$ of WUR-201 is better than Foreign $1 \#$, especially for $\mathrm{BaSO}_{4}$ or $\mathrm{CaSO}_{4}$ scale.

(4) The Influence of $\mathrm{Al}^{3+}$

$\mathrm{Al}^{3+}$ is mainly from the residue of aluminum salt coagulant. Fig. 4 shows the influence of $\mathrm{Al}^{3+}$ on WUR-201 and Foreign 1\# at the dosage of $9 \mathrm{mg} / \mathrm{L}$ and $\mathrm{pH}$ of 8.5. Similar to the influence of $\mathrm{Fe}^{3+}$, the negative effects of $\mathrm{Al}^{3+}$ are also obvious, especially for $\mathrm{BaSO}_{4}$ scale inhibition. For example, when increasing $\rho\left(\mathrm{Fe}^{3+}\right)$ from $0 \mathrm{mg} / \mathrm{L}$ to $0.25 \mathrm{mg} / \mathrm{L}, \quad \eta \mathrm{Ba}$ of WUR-201 decreases from $77.97 \%$ to 46.61\%, while $\eta$ Ba of Foreign 1\# decreases from $65.91 \%$ to $32.39 \%$. In addition, the influence of $\mathrm{Al}^{3+}$ on WUR-201 is smaller than Foreign 1\#.

(5) The Influence of Temperature

For RO system without heating, the inflow temperature varies greatly between winter and summer. Fig. 5 shows the influence of temperature on WUR-201 and Foreign 1\# at the dosage of $9 \mathrm{mg} / \mathrm{L}$ and $\mathrm{pH}$ of 8.5 . It shows that the scale inhibition rates by and large decline in straight line as the temperature increases. It is because that when temperature goes up sulfate scale forming tendency will be promoted. The $\mathrm{BaSO}_{4}$ scale is more sensitive to temperature than $\mathrm{SrSO}_{4}$ and $\mathrm{CaSO}_{4}$.

(6) Scale Inhibition Performance for Calcium Carbonate

Carbonate is the most common scaling substance in all natural water and water with sulfate scale forming tendency must also have the possibility of carbonate scale. When RO system is under the acid addition operation, the problem of carbonate scale can be solved basically. However, because of the fluctuation of the acid content and inflow discharge, sometimes supersaturation phenomenon of carbonate will appear even after adding acid. Therefore, it is better that the sulfate scale inhibitor has also inhibition for carbonate scale.

Fig. 6 shows how the scale inhibition performance of WUR-201 and Foreign $1 \#$ for $\mathrm{CaCO}_{3}$ changes with $\mathrm{pH}$. When adding acid, both of them have strong inhibition for $\mathrm{CaCO}_{3}$, but without the addition of acid the inhibition rate of WUR-201 falls significantly while Foreign 1\# almost loses the inhibition for $\mathrm{CaCO}_{3}$. 


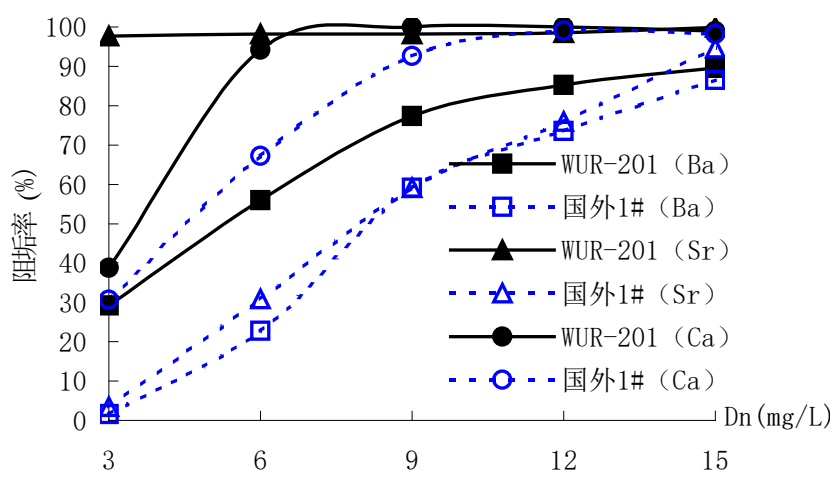

Fig. 1 The Comparison between WUR-201 and Foreign 1\#

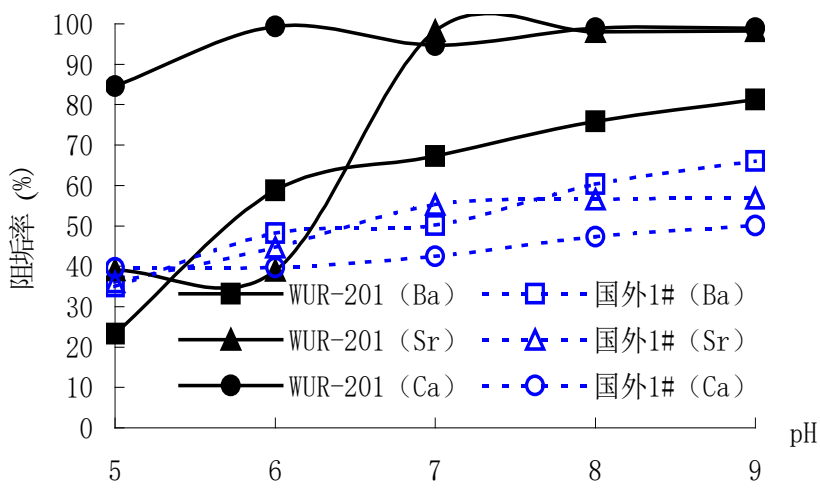

Fig. 3 The Influence of $\mathrm{Fe}^{3+}$ on WUR-201 and Foreign 1\#

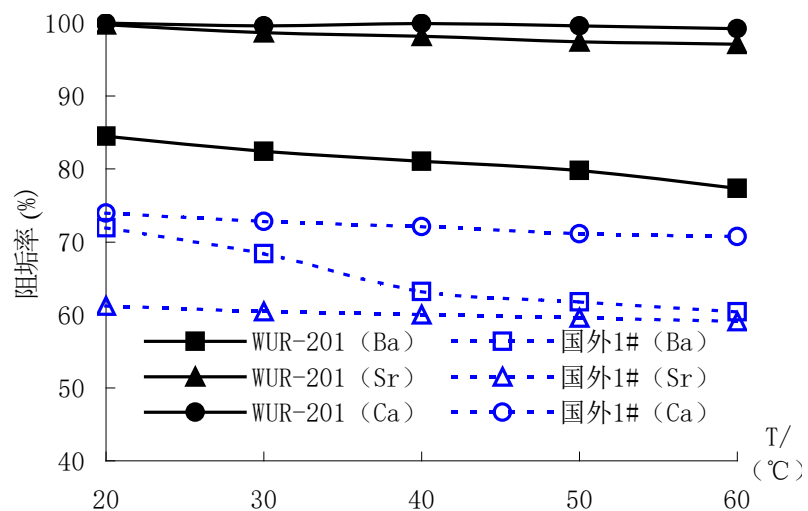

Fig. 5 The Influence of Temperature on WUR-201 and Foreign 1\#

Micro-morphology

Fig. 7 shows the influence of WUR-201 and Foreign 1\# on the morphology of $\mathrm{BaSO}_{4}$ crystal. The crystal becomes smoother under the action of WUR-201, which benefits the carry-over effect of RO concentrate on the scale.

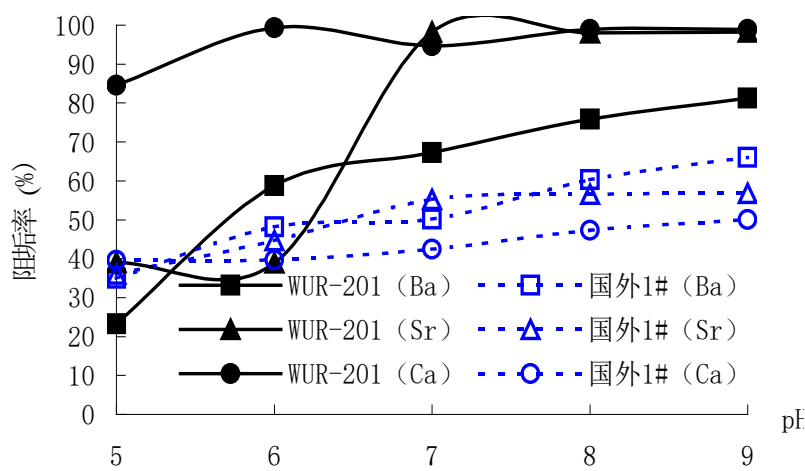

Fig. 2 The Influence of pH on WUR-201 and Foreign 1\#

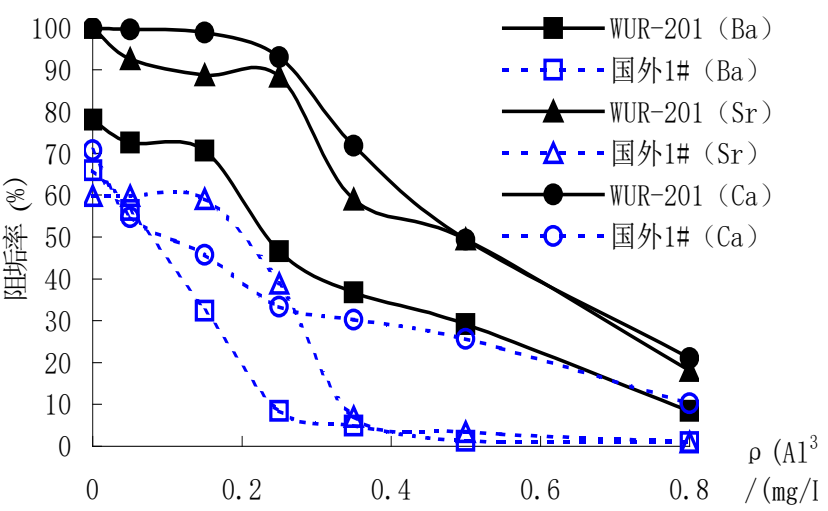

Fig. 4 The Influence of $\mathrm{Al}^{3+}$ on WUR-201 and Foreign 1\#

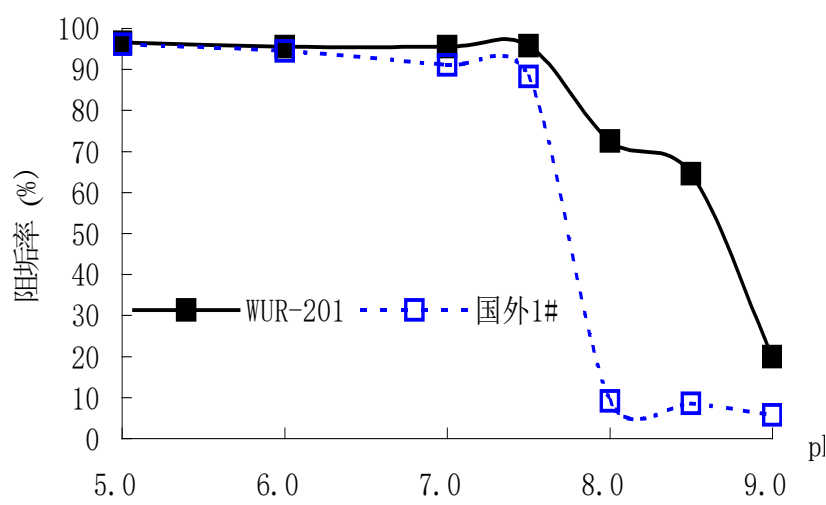

Fig. 6 The Influence of pH on WUR-201 and Foreign 1\# Inhibition for $\mathrm{CaCO}_{3}$ 


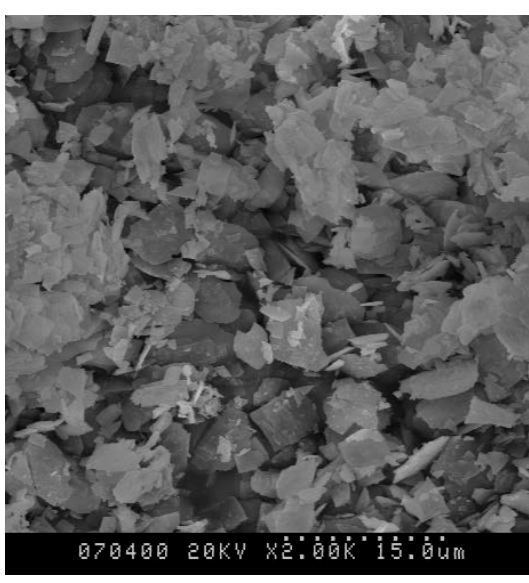

Black Sample

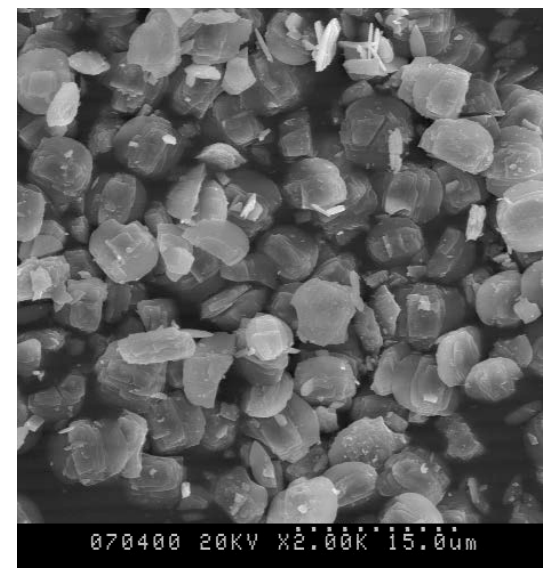

Sample With Foreign 1\#

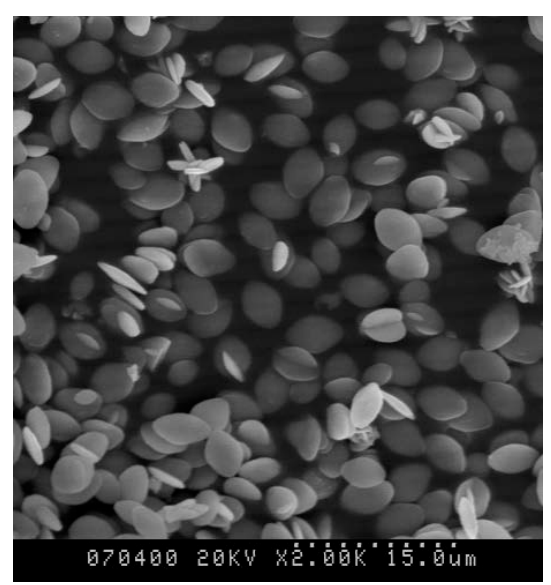

Sample With WUR-201

Fig. 7 SEM of The $\mathrm{BaSO}_{4}$ Crystal $(\times 2000)$

\section{Results}

[1]. The scale inhibition performance of WUR-201 can reach or even exceed Foreign 1\#, and the proper dosage has something to do with the sulfate crystal types. For example, in order to prevent $\mathrm{SrSO}_{4}$ scale the dosage should not be less than 6mg/L (Fig. 1).

[2]. The inhibition performance of WUR-201 increases as $\mathrm{pH}$ increases, so when $\mathrm{RO}$ system is under the acidification operation the dosage should be increased appropriately (Fig. 2).

[3]. $\mathrm{Fe}^{3+}$ and $\mathrm{Al}^{3+}$ have negative effects on WUR-201, leading to WUR-201 poisoning, so $\rho\left(\mathrm{Fe}^{3+}\right)$ and $\rho\left(\mathrm{Al}^{3+}\right)$ should not be more than $0.1 \mathrm{mg} / \mathrm{L}$ in the RO inflow (Fig. 3 and 4 ).

[4]. The scale inhibition rate of WUR-201 declines as the temperature increases, but the declining rate is not large (Fig. 5).

[5]. When $\mathrm{pH}$ is under 8.0, WUR-201 has also good scale inhibition for $\mathrm{CaCO}_{3}$. 